\title{
¿LA DEMOCRACIA LÍQUIDA \\ COMO ALTERNATIVA A LA POLÍTICA CLÁSICA? \\ UN ESTUDIO CONTEXTUAL
}

\author{
Gabriele Vestri
}

SUMARIO: 1. A MODO DE INTRODUCCIÓN. 2. LA CUESTIÓN DEMOCRÁTICA. 3. LA DEMOCRACIA LíQUIDA. 3.1. La sociedad del conocimiento. 3.2. El posible cuerpo electoral. 3.3. La delegación del voto. 3.4. El Parlamento virtual. 4. CONClusiones. 5. Bibliografía ESENCIAL.

«Si hubiera un pueblo de Dioses, se gobernaría Democráticamente»

Jean-Jacques Rousseau, El contrato social

Libro III, Capítulo IV

\section{A MODO DE INTRODUCCIÓN}

El Siglo XXI, en materia de democracia y debido a la actual crisis económica y de sistema, se caracteriza por el replanteamiento de la participación política de los ciudadanos. Es conocido que la participación política emana de conceptos más clásicos como el de democracia representativa, directa y participativa y aunque en los últimos años se están asomando nuevos criterios de participación, por ejemplo la democracia liquida objeto de este estudio, no podemos desconocer a priori las ideas básicas de participación democrática.

Debemos entonces, aunque brevemente, plantear una posible categorización de indicando tres arquetipos de democracia y entonces de participación: 
a) la democracia directa, b) la democracia representativa, c) la democracia participativa.

En términos generales y en palabras de Giovanni Sartori, «la democracia que debemos comprender es la democracia política destinada a reducir las múltiples voluntades de millones de personas a una jefatura única» ya que «la democracia política es aquella que opera en las peores condiciones posibles y no hay que pretender de una democracia a gran escala lo mismo que se puede esperar de una democracia en pequeña escala» ${ }^{1}$.

También es cierto que una parte de la doctrina dogmatiza que el prototipo de democracia representativa y el de democracia directa con el tiempo han aprendido a coexistir aunque en la perspectiva del Prof. Donati, «la democracia directa parece englobarse en la representativa con lo cual queda aun más importante entender el concepto de democracia participativa como tercer grupo fundamental» ${ }^{2}$.

En esta línea, Pitking decía que la cuestión de la representación radica en saber por qué los gobernantes, equipados con tales poderes, habrían de actuar en beneficio del interés de otros, de los ciudadanos, o al menos de cierta mayoría de ellos. Esto es lo que queremos significar con representación: actuar de acuerdo con los mejores intereses del público ${ }^{3}$

En este sentido, la percepción de la democracia representativa parece identificarse con la consolidación de la idea de Estado-Nación del Siglo XIX, instalada por la revolución industrial y aceptada por la revolución burguesa. Sin embargo hoy día este tipo de democracia, que todavía sigue vigente, se encuentra frente a nuevos desafíos y pasa inevitablemente por dificultades que abren camino a la noción de democracia participativa. En primer lugar, si como es cierto la democracia representativa es el signo distintivo del Estado-Nación, nos encontramos frente al débil alcance de este tipo de «demos». Actualmente, asuntos que tienen origen fuera de los confines nacionales logran interés y tienen repercusiones en las sociedades nacionales (problemas medioambientales, conflictos, flujos de capitales etc..). Esto nos llevaría entonces a replantearnos el fenómeno de la mundialización y su sistema de gobierno, es decir, lo que los analistas, politólogos y juristas reconocen como la democracia cosmopolita con la constitución entonces de un poder demo-

1 SARTORI, G. ¿Qué es la democracia? Madrid, Tarus, 2012, pág. 14.

2 Vid. Donati, D. Partecipazione come categoría. Identitá e raprresentanza. Ruolo e contraddizioni delle nuove forme associative en VALASTRO, A. Le regole della democracia partecipativa. Itinerari per la costruzione di un método di governo. Napoli: Jovene Editore, 2010, pág. 154.

3 PitKIn, Hanna F. The Concept of Representation. Berkeley: University of California Press, 1967. 
crático mundial ${ }^{4}$. Si esto fuera viable, se debería circunscribir la labor de los poderes nacionales, tema muy complicado de cara a las peticiones nacionalistas y federalistas dentro de los territorios nacionales. En esta línea podría entonces generarse un desequilibrio entre los límites internos (descentralización del poder) y los límites de naturaleza externa (por ejemplo: las organizaciones internacionales).

Por otro lado, la democracia representativa deberá lidiar con su debilidad acerca del tema de la participación ciudadana. Es por eso que en el Siglo XXI, el concepto histórico de democracia representativa se advierte superado a favor de un sistema participativo de los ciudadanos.

Avala esta teoría la misma estructura del actual sistema democrático. En España la participación ciudadana se reduce al voto cada cuatro años, no existe una verdadera continuidad en la relación entre el poder político y los electores. Tras las elecciones las instituciones creadas quedan aisladas de la ciudadanía y de sus intereses. Los poderes de las instituciones políticas se instauran a través de partidos políticos que en algunas ocasiones limitan la representación de sus electores. Finalmente, la democracia representativa, con el tiempo, ha creado «políticos con cargos» y con voluntad de permanencia, poco perceptivos del sentir ciudadano 5 .

A la luz de diferentes experiencias podemos afirmar que la democracia participativa supone la información, consulta, control e incluso decisión de la comunidad sobre aspectos de las políticas públicas. Lo importante es el fondo de la propuesta que consiste en la influencia real de la sociedad civil sobre la sociedad política.

Hoy en día entonces la pérdida de confianza, la repulsión hacia una clase política corrupta y distante, ha generado en la ciudadanía la necesidad de auto organización para enfrentarse a las complicaciones sociales y económicas de la vida cotidiana.

Si por un lado el sujeto destinatario de la democracia sigue siendo el mismo, es decir, el ciudadano, por el otro parece cambiar la herramienta de ejercicio de esta libertad constitucionalmente garantizada. A esto se suma la desconexión de lo meramente político para redescubrir lo comunitario, a lo que una parte de la doctrina ha llamado la «teoría del nos». Conforme a esta lectura se alinea Jean-Luc Nancy que identifica al pueblo de una nación como

${ }^{4}$ En este sentido entre otros Vid. Ganuza Fernández, E., Álvarez De Sotomayor, C. Ciudadanía y democracias: los presupuestos participativos en GANUZA FERNÁNDEZ, E., Álvarez De Sotomayor, C (Coords.) Democracia y presupuestos participativos. Barcelona: Icaria, 2003, págs. 16 y ss.

${ }^{5}$ En materia de conexiones políticas Vid. Blanco VALdÉs R.L., Las conexiones políticas. Madrid: Alianza Editorial, 2001. 
lo que se ocupa ahí, trabaja ahí, vive ahí ${ }^{6}$. Es indudable en esta línea que la unidad del Pueblo se solidariza para combatir contra una clase política minoritaria y que ya no representa las exigencias de sus votantes.

Es nuestra obligación entonces, aunque brevemente, posicionarnos sobre la cuestión democrática no solamente asumiendo los criterios generales que la identifican sino, más bien, examinando la relación entre el concepto de democracia formal y los más modernos sistemas que pasan a través de la democracia participativa y se concretan con procesos tecnológicos hasta hace poco tiempo desconocidos. La democracia líquida, un concepto derivado de la teoría de la modernidad liquida acuñada por Zygmunt Bauman es por lo tanto una de las consecuencias de una democracia participativa aplicada a casos determinados ${ }^{7}$.

No debemos olvidar que junto a la democracia líquida se conocen supuestos como los presupuestos participativos, las reuniones asamblearias de barrios, los towns meetings, que crean y realizan la democracia participativa, identificándola, a veces, como único escudo de lucha contra la política clásica.

Al centro de estas nuevas posturas están los ciudadanos que demandan una relación más directa con la política clásica, intentando favorecer una new policy basada en las comunicaciones virtuales, las redes sociales y más en general, en internet y en sus potencialidades presentes y futuras.

El mismo Norberto BobBio, aunque no haciendo referencia a la red digital, en el año 1985 entendió que la democracias directa y representativa ya no eran suficientes y de hecho indicó que «el proceso de ampliación de la democracia en la sociedad contemporánea no se presenta solamente a través de la integración de la democracia representativa con la democracia directa, sino también, y sobre todo, mediante la extensión de la democratización, entendida como institución y ejercicio de procedimientos que permiten la participación de los interesados en las deliberaciones de un cuerpo colectivo, en cuerpos diferentes de los políticos ${ }^{8}$.

Aunque tomaremos en cuenta el actual caso español y cuestiones concretas del sistema italiano (tras la presencia del Movimiento 5 Stelle y su nueva forma de hacer política), muchas de las consideraciones pueden encontrar aplicación en cualquier país que se esté replanteando la manera de reconstruir la democracia.

${ }^{6}$ Vid. NANCY, J.L., «La verdad de la democracia», Amorrotu Editores, Buenos Aires-Madrid, 2009, pág. 98.

7 Bauman, Z., «Modernidad Liquida», Fondo de Cultura Económica, USA, 2003.

${ }^{8}$ BobBio, N., «Estado, gobierno y sociedad: por una teoría general de la política», Editorial Fondo de Cultura Económica, México, 1989, pág. 218. 


\section{LA CUESTIÓN DEMOCRÁTICA}

Disertando sobre la diferencia entre democracia liberal y popular, los autores Ulrich Rödel, Günter Frankenberg y Helmut Dubiel nos indican que en ambos casos se intenta lograr los mismos objetivos, es decir, la soberanía popular y la autodeterminación aunque, con estrategias diferentes. En el caso de la democracia liberal, a través del sufragio universal, el sistema representativo, la distribución de la riqueza y la primacía de los derechos individuales; mientras que en la democracia popular, mediante el monopolio del poder del Partido, la unidad de la clase trabajadora y del pueblo?.

En la base del discurso está la persona, el individuo que identifica el verdadero núcleo en torno al cual circulan los principios fundamentales de libertad e igualdad que se deberían concretizar en la participación en la esfera pública que en palabras de Luigi Ferrajoli, "'Esfera pública», es el lugar de la política que se refiere a los intereses de todos, en oposición a la 'esfera privada', que se refiere al interés de los individuos y por tanto es el lugar privilegiado de la economía» ${ }^{10}$.

Sin embargo, presentando la cuestión democrática, tenemos la obligación de avisar sobre las amenazas a las democracias más consolidadas por parte de un sistema financiero global al servicio del capitalismo. El fenómeno no es nuevo. Las disputas ideológicas sobre el futuro de la idea socialista que surgió con las grandes revoluciones y reformas del siglo XX parecen no inquietar a los partidos políticos de izquierda, teóricamente más cercanos al socialismo popular. Con excepción de algunas corrientes, como los representantes del viejo proletariado del siglo XX, los socialistas actuales, diseminados alrededor de los diversos partidos comunistas, socialistas y socialdemócratas del mundo, escasamente han avanzado en esta discusión. Hoy en día se presenta por lo visto una vez más este problema.

Latinoamérica, que no es ajena a esta situación, debe también enfrentarse a una posible coalición con los partidos políticos que se reconocen en la designada «ola rosa». Países como Venezuela, Ecuador, Bolivia, Uruguay se sitúan al margen de los partidos históricamente socialistas y también de aquellos comunistas. Esto parece generar un «tripolarismo» donde las luchas políticas entre las derechas, las izquierdas y la «ola rosa» necesitan una fuerte base democrática $\mathrm{y}$, por ende, una enérgica y dinámica realización demo-

9 Rödel, U., Frankenberg, G. y Dubiel, H., «La cuestión democrática», Huerga y Fierro Editores, Madrid, 1997, pág. 35.

${ }^{10}$ FerRajoli, L., «De la carta de Derechos a la formación de una esfera pública europea», en CARBONELl, M., SALAZAR, P. (editores), "La constitucionalización de Europa», Universidad Nacional Autónoma de México, Instituto de Investigaciones Jurídicas, México, 2004, pág. 79. 
crática frente a los ciudadanos que reconocen en la falta de justicia social el verdadero problema.

En este sentido los partidos políticos, sobre todo los de la izquierda europea, tienen por delante un desafiante reto: el replanteamiento de la cuestión democrática a través de la igualdad. El razonamiento debe tomar su punto de partida en la comprensión de que la igualdad no es sinónimo de derecho a la igualdad. En su significado político y legal asumimos que la igualdad puede ser formal (porque una ley lo dice), puede ser frente a la ley (para que nos juzguen sin hacer distinción con respecto a nuestras circunstancias personales), pero los ciudadanos exigen una igualdad real que no puede identificarse con el hecho de que todos y todas tengamos lo mismo. La percepción de la igualdad, entonces, tiene características de correspondencia y proporción es decir cada persona hace su propio camino y en consecuencia de él obtiene lo que le corresponde o el que más desea. El derecho a la igualdad es el verdadero pilar para la reconstrucción de la cuestión democrática. Los partidos políticos deben revitalizar la lucha para que el derecho a la igualdad se identifique con el reconocimiento de la paridad de las condiciones de partida. Es esto lo que sin lugar a dudas demandan los ciudadanos europeos. La corrupción política, el nepotismo, los privilegios y el avance de los que siguen beneficiándose de la actual crisis económica europea (y mundial) representa el desencadenante de las protestas. No se trata entonces simplemente de exigir un cambio político sino más bien de clamar un cambio en la manera de hacer política. Los ciudadanos demandan tomar las riendas de la política utilizando sistemas más modernos que ya no cuenten (directamente) con el sistema político clásico y con ello, lograr el propósito de construir un sistema democrático participativo e informado.

Sólo los partidos políticos que entiendan este diferente sistema de hacer política podrán enfrentarse, en los años venideros, a las exigencias ciudadanas. La flexibilidad de las relaciones entre partidos políticos para el bien de un país resultarán indispensables. Los partidos políticos que sigan aferrados a meras lógicas de poder, tarde o temprano, estarán constreñidos al olvido ${ }^{11}$.

${ }^{11}$ Ha sido el caso, por ejemplo, del Partido Comunista Italiano en los años ochenta y del siguiente Partido de la «Rifondazione Comunista» en los años noventa así como, más recientemente el caso de «Alleanza Nazionale» de Gianfranco Fini. En el primer caso, después del rapto y homicidio del Presidente de la Democracia Cristiana, Aldo Moro, se rompe forzadamente el famoso «Compromiso histórico» entre este último y el Secretario del Partido Comunista Italiano EnRICO BERLINGUER. A partir de este momento y debido a la imposibilidad de encontrar un acuerdo entre el Secretario del PCI y el Secretario del Partido Socialista Italiano (PSI) BETTINO CRAXI, el comunismo italiano inicia su parábola descendente. En ambos casos no se trata solamente de diferencias políticas sino más bien de establecer las prioridades del país. Los dos partidos siguen anclados a los ideales históricos que los identifican perdiendo de hecho el contacto con las exigencias de los ciuda- 
Sin embargo, la clase política actual no parece darse cuenta de la importancia de reformar drásticamente la política clásica y es por eso que en casos (todavía) puntuales los ciudadanos dejan de identificarse con un partido político a favor de nuevos Movimientos que cada vez más surgen en respuesta a la descompuesta y fragmentaria política de partido y que no se reconocen en una idea política circunscripta ${ }^{12}$.

\section{LA DEMOCRACIA LÍQUIDA}

En el contexto descrito es una labor esencial plantear los posibles instrumentos a través de los cuales posibilitar un histórico cambio en la manera de hacer política para reconstruir la cuestión democrática. Es cierto que la sociedad civil demanda condiciones más participativas y deliberativas en el mundo institucional y social; la idea es promover políticas deliberativas que lleven a la comunidad a tomar decisiones ${ }^{13}$.

La consideración de estos temas debe ser constructivamente crítico.

Al más general concepto de democracia participativa y «que tiene entre sus efectos la desconexión entre gobernantes y gobernados, la ruptura del vínculo representativo entre representados y representantes y el distanciamiento del ciudadano de la vida pública» ${ }^{14}$, se suma el que se conoce como «democracia líquida» cuya participación se despliega a través de las nuevas tecnologías y más en concreto mediante internet.

En los diferentes portales internet que tratan la idea de democracia liquida, no se encuentra una definición univoca de esta nueva y posible experiencia. A lo largo de este trabajo indicaremos los elementos que caracterizan la democracia liquida pero creemos interesante intentar definir el concepto de

danos. En el segundo caso, el Partido de la «Rifondazione Comunista» empieza a desaparecer cuando su Secretario FAUSTo BeRTiNOTTI en el año 1998 quita la confianza al precario gobierno de la Izquierda Democrática representado por Romano Prodi. Una vez más las lógicas de la política clásica prevalecen sobre el bien del país. El Gobierno Prodi dimite y Rifondazione Comunista sale a tiempo indefinido del escenario político Italiano. El último caso vio una verdadera lucha de poder entre Gianfranco Fini, Presidente de Alleanza Nazionale y en aquel entonces Presidente de la Cámara de Diputados y el Presidente del Gobierno SILVIO BERLUSCONI. El poder para prevalecer sobre el otro acabó con Gianfranco Fini cuya consecuencia fue la desaparición de su Partido político.

${ }_{12}$ Es el caso del italiano Movimiento 5 Stelle del que tendremos ocasión de hablar más detenidamente.

13 En este sentido, Vid. CARdenas García, J., «Democracia interna en los partidos y democracia participativa»,[En línea].

www.juridicas.unam.mx/publica/librev/rev/derestas/cont/1/.../ens8.pdf, pág. 151 .

14 RAMiRez NÁRDIZ, A., «La participación como respuesta a la crisis de la representación: el rol de la democracia participativa» en Revista de Derecho Político, núm. 90 mayo-agosto 2014, pág. 196. 
democracia liquida que finalmente es el resultado de las características que analizaremos. La democracia liquida es la suma de la democracia directa y participativa que se desarrolla a través de nuevas tecnologías que logran superar el límite representativo al que la ciudadanía le tiene rechazo y que identifican con la actual clase política.

En este sentido entonces podemos decir que las dos figuras pueden ser compatibles y complementarias es decir la democracia participativa-directa engloba la democracia líquida como herramienta técnica para construir una política participativa.

Según el portal web «democracialiquida.org», se trata de que a cada ciudadano se le reconozca la posibilidad de votar las decisiones y realizar propuestas, mediante su voto o cediéndolo a un representante para aquellas decisiones en las que prefiere no participar. En una democracia líquida, los ciudadanos que desean implicarse en la vida política, pueden hacerlo, y los que optan para no involucrarse, pueden acudir a representantes. Así mismo, cualquier ciudadano o grupo de ciudadanos puede crear un representante virtual, que publicará su intención de voto en nombre del partido político o corriente de opinión a la que representa» ${ }^{15}$.

Los pilares de la democracia líquida son entonces fundamentalmente dos: la delegación del voto y la construcción de un Parlamento Virtual. Si embargo estos dos elementos no pueden tener aplicación si previamente no identificamos el escenario en que deberían impulsarse.

La preocupación no reside en la utilización de internet para participar en la política de un país -los avances tecnológicos son imparables y más temprano que tarde el Parlamento virtual si no será una realidad, por lo menos será una posibilidad concreta- más bien se levantan algunas inquietudes sobre quién y cómo se gestionarán, filtrarán y utilizarán las informaciones que almacenadas en la sociedad de la información se catapultan en la sociedad del conocimiento.

De hecho, muchos logros, avances y actividades del hombre presentan una doble cara, una buena y la otra mala, y el conocimiento, resultado de los avances científicos y tecnológicos, quizás con más claridad que ningún otro, presenta esa doble faceta ${ }^{16}$.

En este mismo sentido, la sociedad de la información y la del conocimiento resultan ser dos vertientes fundamentales que aunque compartiendo elementos comunes, se caracterizan por ser autónomas no pudiendo entonces asumir que la posible democracia líquida se desenvuelva indistintamente en una de las dos vertientes. En nuestra opinión, para que la democracia líquida obtenga algún tipo de resultado es necesaria una sociedad del conocimiento

15 En este sentido Vid. portada principal de www.democracialiquida.org.

16 En este sentido Vid. Mateo, J.L., «Sociedad del conocimiento», Arbor Ciencia, Pensamiento y Cultura, Vol. CLXXXII núm. 718 marzo-abril, Madrid, 2006, pág. 147. 
libre de servilismo. Los únicos que podrán conseguir esta independencia serán los ciudadanos que crítica y selectivamente se apropien de la información y la utilicen para participar activamente en la construcción primeramente de una idea política individual y después de una política democrática. Se trata de identificar una verdadera sociedad civil global de la información como conjunto de la sociedad del conocimiento y la sociedad del saber ${ }^{17}$.

Tenemos que entender la sociedad de la información como un gran contenedor donde gracias a las nuevas tecnologías se acumulan grandes cantidades de informaciones que rápidamente se difunden llegando a la comunidad social. La labor de este tipo de sociedad termina cuando la noticia llega a su destinatario y es en este momento que debe intervenir la sociedad del conocimiento para filtrar las informaciones y convertirlas en herramientas democráticas de participación.

\subsection{La sociedad del conocimiento}

El conocimiento es entonces elemento fundamental para que los ciudadanos puedan expresar su voto. Esta obviedad es cierta en la política clásica y si cabe lo es aún más en la democracia líquida. En este último caso el desafío es mayor puesto que las nuevas tecnologías e internet sí son de alcance general pero atañen una población particularmente específica.

Dentro de este marco y para construir un sistema de información completamente abierto, acrítico, la democracia líquida deberá enfrentarse, entre otros, al problema del «sistema de recomendación». En este momento la red identifica las preferencias del usuario (en relación a sus búsquedas) y propone temas parecidos de los cuales el internauta se convierte en destinatario privilegiado. Esta situación arriesga la libre construcción de la idea política y social del receptor. El sociólogo alemán Ulrick Beck en un libro del lejano 1986, apuntaba que estábamos en camino hacia una nueva modernidad donde el eje que organiza nuestras sociedades no es tanto la distribución de bienes sino más bien la distribución de males, es decir la distribución del riesgo. Beck llama a este estado de cosas «sociedad del riesgo» ${ }^{18}$. Es cierto que vivir en este tipo de sociedad puede conllevar una paulatina presencia de decisiones arriesgadas dentro de la conducta individual como la acción de imputar responsabilidades a ciertos agentes sociales no políticos ${ }^{19}$.

${ }^{17}$ En este sentido Vid. Cela, J., «Sociedad del conocimiento y sociedad global de la información: Implantación y desarrollo en España», Documentación de las Ciencias de la Información, España, Vol. 28, 2005, pág. 151.

18 BeCK, U., "Risk Society: Towards a New Modernity», Londres, 1986.

19 Vid. López Cerezo, J., «Gobernabilidad en la sociedad del conocimiento», Eidos Revista de Filosofia de la Universidad del Norte, núm. 6, mayo, Colombia, 2007, pág. 128. 
Sin embargo, hoy en día parece insostenible una vuelta atrás, dicho de otra forma tenemos que convivir con esta situación intentando marcar líneas guías decididas para que la sociedad del (riesgo) conocimiento no se convierta, aún más, en la sociedad del anacronismo y la equivocación.

Directamente relacionado con este último tema es el pensamiento de una parte de la doctrina que de manera tajante relata sobre la diferencia que hay entre el conocimiento y el saber. De hecho, la sociedad globalizada encuentra en la sociedad del conocimiento un valioso aliado pero no podemos afirmar lo mismo para la sociedad del saber. Esta última es una etapa más avanzada de la sociedad del conocimiento puesto que «el saber forma parte de lo más humano de los seres humanos, es parte de lo más humanizado de todos nosotros, es una característica de la humanidad más humana, de su naturaleza más íntima, de su constitución más basal. El saber puede definir a la persona, el conocimiento menos. El saber es la trascendencia del conocimiento ${ }^{20}$.

A esta altura entonces podemos sí afirmar que la democracia líquida deberá moverse en la sociedad del saber como una más ambiciosa sociedad del conocimiento.

A nivel práctico la utilización de las nuevas tecnologías, en particular internet, sigue siendo, en esta materia, una prioridad. Según los datos de ComScore, en su último Informe «Spain Digital Future in Focus 2013», el total de internautas españoles se eleva a 17 millones de usuarios diarios (incremento del 9\% con respecto al año 2011 ${ }^{21}$. Es en este tipo de entorno que entonces se ha desarrollado la sociedad del conocimiento y a medio plazo la democracia líquida.

\subsection{El posible cuerpo electoral}

La Asociación para la Investigación de Medios de Comunicación y EGM divide la población española en siete franjas de edad. El mayor porcentaje de utilizadores de internet tiene una edad comprendida entre los 25 y los 44 años. Se registra un leve aumento, en el último año, de usuarios de edad comprendidas entre los 45 y los 54 años de edad. Llaman la atención los todavía bajos porcentajes de usuarios de 20 a 24 años, de 55 a 64 años y más de 65 años. Aparte, interviene el caso de las personas que tienen una edad comprendida entre los 14 y los 19 años. Actualmente, las personas de entre 14 y 17 años, es decir la mayoría de la franja considerada, no representan parte del

${ }^{20}$ LARA GonZÁlez, J. D., «Sociedad del conocimiento en medio de una sociedad del desconocimiento», Nómadas Revista Crítica de Ciencias Sociales y Jurídicas, Vol. 32 núm. 4, España, 2011, págs. 221-253.

${ }^{21}$ Vid. http://www.digital-nature.com/uploads/documentos/2013-Spain-Digital-Future-in-Focus.pdf

[Fecha de consulta 9 de diciembre de 2013]. 
cuerpo electoral con lo cual en este momento quedan excluidos de la «participación líquida». No sobra recordar que para ejercer el voto en España es necesario tener cumplidos los dieciocho años. Por otro lado, es interesante destacar que las personas mayores (55-65 años) hacen una utilización de internet drásticamente reducida con respecto a otras franjas de edad.

\section{Figura 1. Evolución Internet en España}

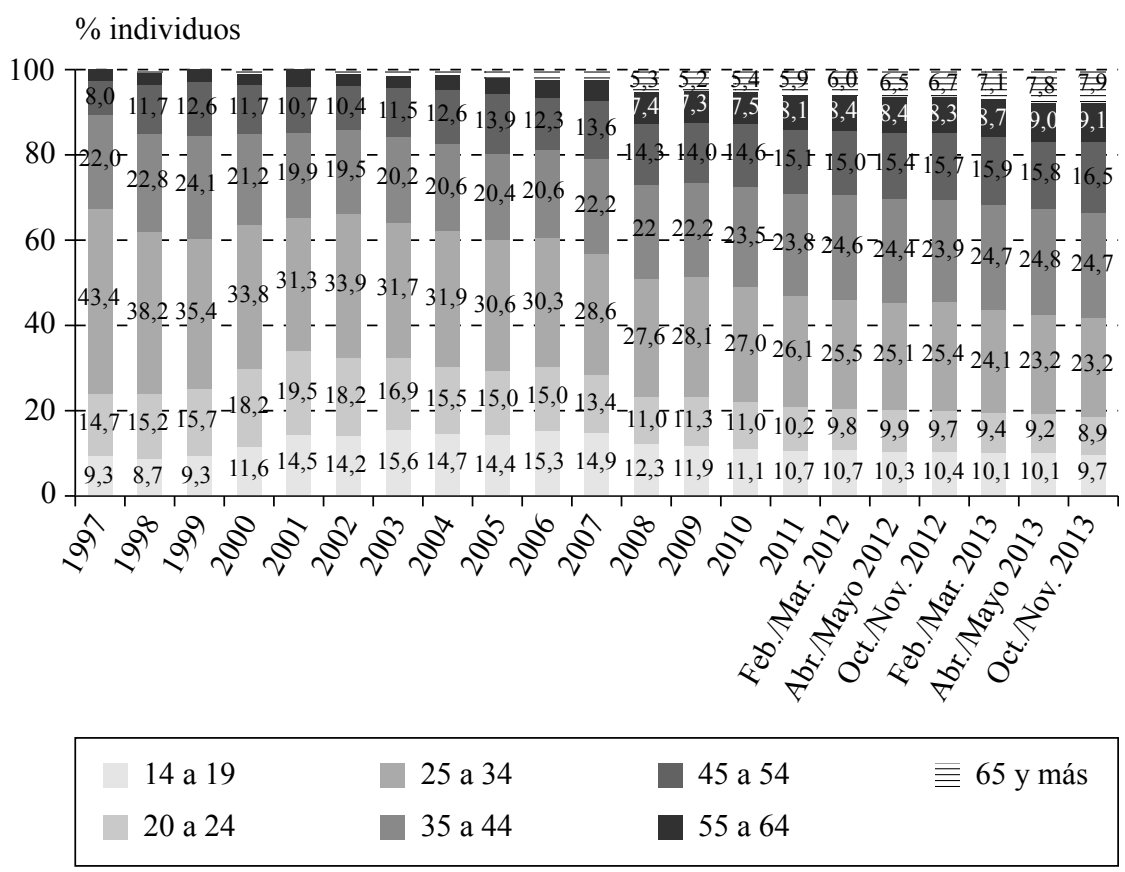

Fuente: EGM 2013. www.aimc.es.

Estos, que podrían parecer meros (y elementales) datos estadísticos, resultan substanciales para nuestra investigación. Es interesante verificar cual podría ser el cuerpo electoral ventajoso para la democracia líquida.

El Instituto de Estadística Español otorga una proyección de población con derecho al voto (2006-2020) dividida por edades ${ }^{22}$. Si asumimos como

${ }^{22}$ La presente estadística incluye dos escenarios: el primero considera el derecho al voto a partir de los 18 años, el segundo a partir de los 16 años. 
referencia el año 2014, España cuenta con 33.017.972 personas con derecho al voto ${ }^{23}$. El número mayor se ubica en la franja de edad comprendida entre los 30 y los 64 años (20.489.586) reflejando, con pocos ajustes al alza, la trayectoria de los usuarios de internet.

Figura 2. Evolución de la población española con derecho a voto, por grupos de edad, 2006-2020

\begin{tabular}{|c|c|c|c|c|}
\hline \multirow{2}{*}{ Año } & \multicolumn{2}{|c|}{ Menores de 30 años } & \multirow{2}{*}{ 30-64 años } & \multirow{2}{*}{65 o más años } \\
\hline & Escenario B & Escenario A & & \\
\hline 2006 & 6.592 .671 & 7.435 .680 & 19.639 .350 & 7.281 .226 \\
\hline 2007 & 6.334 .687 & 7.164 .727 & 19.906 .570 & 7.244 .159 \\
\hline 2008 & 6.093 .070 & 6.907 .053 & 20.125 .355 & 7.234 .547 \\
\hline 2009 & 5.856 .842 & 6.666 .164 & 20.273 .922 & 7.278 .662 \\
\hline 2010 & 5.647 .767 & 6.443 .537 & 20.386 .007 & 7.320 .508 \\
\hline 2011 & 5.463 .859 & 6.226 .775 & 20.454 .036 & 7.380 .058 \\
\hline 2012 & 5.294 .431 & 6.036 .860 & 20.518 .263 & 7.408 .132 \\
\hline 2013 & 5.135 .970 & 5.870 .632 & 20.539 .230 & 7.448 .216 \\
\hline 2014 & 5.003 .177 & 5.737 .702 & 20.489 .586 & 7.525 .209 \\
\hline 2015 & 4.884 .565 & 5.617 .506 & 20.447 .918 & 7.572 .992 \\
\hline 2016 & 4.789 .008 & 5.526 .997 & 20.407 .557 & 7.596 .613 \\
\hline 2017 & 4.706 .654 & 5.468 .704 & 20.341 .888 & 7.624.339 \\
\hline 2018 & 4.648 .568 & 5.429 .503 & 20.233 .554 & 7.677 .689 \\
\hline 2019 & 4.612 .869 & 5.401 .896 & 20.117 .645 & 7.727 .782 \\
\hline 2020 & 4.587 .027 & 5.391 .447 & 20.001 .319 & 7.771 .193 \\
\hline \multicolumn{5}{|c|}{ Variación 2008-2020 } \\
\hline Cifras absolutas & -1.506 .043 & -1.515 .606 & -124.036 & 536.646 \\
\hline Porcentaje & $-24,7$ & $-21,9$ & $-0,6$ & 7,4 \\
\hline
\end{tabular}

Fuente: Instituto de Estadística Nacional de España.

${ }^{23}$ Considerando los 18 años como edad para votar. 
A propósito entonces del posible «cuerpo electoral» necesario para llevar a cabo el programa de la democracia líquida cabe destacar que a la luz de la interpretación de los diferentes datos (fundamentalmente: usuarios diarios de internet y proyección del cuerpo electoral), resulta que el número de personas que diariamente utiliza internet (17 millones) independientemente de la edad representa poco más que la mitad del cuerpo electoral del año 2014 (33 millones). Dicho de otra forma, parece que la población útil a la democracia líquida resulta ser exactamente la mitad de la que puede ejercer el voto.

A eso se suma el gran reto de sensibilizar las franjas de edades más jóvenes y las mayores para que no utilicen internet como mera herramienta social (en el caso de los jóvenes) o de información específica (en el caso de los mayores) sino más bien como nueva forma de hacer política.

Al mismo tiempo entendemos que la idea de la democracia líquida es descaminar, de alguna manera, conceptos clásicos como elector, cuerpo electoral etc., pero no podemos olvidar que para que una decisión se lleve a cabo es necesario un camino político que debe pasar por la soberanía popular. A pesar entonces de cómo se tomará la decisión (las nuevas tecnologías representan un punto de fuerza), resulta esencial establecer quién podrá tomar la decisión. Por eso, la expresión «cuerpo electoral» puede ser substituida con, por ejemplo, «censo ciudadano» (término aparentemente menos anclado a la política clásica) pero a nivel axiológico sigue identificando los que pueden ejercer legalmente su participación política activa que desemboque, esto sí, en una toma de decisión.

\subsection{La delegación del voto}

Los partidarios de la democracia líquida identifican la delegación del voto (y la delegación del voto digital) como uno de los puntos cardinales de la política democrática digital. Técnicamente se trata de confiar el voto a un representante experto por cada materia de actuación. Se asiste entonces a una modalidad que en sus características jurídicas y generales identifica un mandatario que cumple con instrucciones ${ }^{24}$. Esta técnica no menoscaba la participación directa es decir, el ciudadano recurrirá a la delegación sólo en los casos que no tiene interés o competencia para expresarse conscientemente sobre un tema concreto. Este sistema además incluye la «delegación transitiva» donde el nombrado representante puede delegar a otros representantes estableciéndose así verdaderas cadenas de confianza que canalizan los votos ${ }^{25}$.

${ }^{24}$ Vid. SARTori, G., «Elementi di teoría politica», Il Mulino, Italia, 1989, pág. 142.

${ }_{25}$ Vid.http://www.democracialiquida.org/sect/es_ES/4003/Delegaci\%C3\%B3n+de+ Voto.html 
A nivel constitucional, esta práctica no tiene el mismo fundamento que perciben los seguidores de la democracia liquida; mientras que sí, encuentra un reconocimiento jurídico más directo en el derecho privado o en el derecho societario. Es el caso, por ejemplo, de la propiedad horizontal cuando un condómino delega otra persona para que vote en su lugar, así como cuando se alcanza la delegación durante una asamblea de accionistas con derecho de asistencia que podrán conferir la representación a un tercero para que ejerza el voto.

Como se apuntaba, la Constitución Española de 1978 y la Ley Orgánica del Régimen Electoral General (L.O. 5/1985 de 19 de junio) no reconocen la posibilidad de delegar el voto (entendemos una delegación directa cuando el titular del derecho de sufragio cede su voto a un tercero). Es cierto que el art. 23.1 de la Constitución Española utiliza la palabra representante pero su significado, notoriamente, hace referencia a la elección de los que, elegidos mediante sufragio universal, representarán los ciudadanos en el Parlamento. $\mathrm{Al}$ estado actual, entonces, en la construcción de una nueva forma de hacer política pública participativa, la delegación del voto no encuentra ningún respaldo legal (y constitucional).

Desde una perspectiva puramente jurídica, entendemos que a una materia tan importante como la de la participación política de un país, siempre debe corresponder un dato legal que legitime las acciones consecuentes. En este sentido, la delegación del voto parece una práctica utópica, no irrealizable, pero ilusoria puesto que debería plantearse la reforma de la Constitución y la aprobación de un procedimiento que transforme drásticamente uno de los más importantes derechos fundamentales.

Tras esto, cabe señalar que quizá la delegación del voto esconde la necesidad de asumir que los ciudadanos deben tomar las decisiones que les afectan, directamente sin las aportaciones, concretas o presuntas, de los representantes políticos que se quedan sometidos a las lógicas de partido.

\subsection{El Parlamento virtual}

El segundo pilar de la democracia líquida (junto con la delegación del voto) es la creación de un Parlamento virtual que deberá reemplazar el Parlamento tradicional. En realidad, la creación de este tipo de institución virtual resulta más compleja de lo que parece y de hecho, se trata solamente de la última fase de este traspaso entre un organismo clásico a favor de uno que representa la era 2.0.

En este sentido, El Parlamento Virtual consentirá, siempre según la visión de los partidarios de la democracia liquida, que cada ciudadano ocupe su

[Fecha de consulta 10 de diciembre de 2013]. 
escaño y pueda votar, realizar propuestas o delegar su voto en los representantes que elija (por eso la importancia de la delegación del voto) a través de las nuevas tecnologías ${ }^{26}$.

A tal propósito y para garantizar la identidad del ciudadano y comprobar la legalidad de su voto, se utilizará el documento de identidad electrónico que entre otras opciones, incorporará funciones criptográficas de identificación y firma digital ${ }^{27}$.

Lo que resulta evidentemente significativo es investigar sobre la realización del traspaso de poder entre el Parlamento actual y el Parlamento virtual. La respuesta por los partidarios de la democracia líquida es la creación del Partido de Internet. Se trata de un partido sin ideología política. Un partido que sirve como trámite entre los ciudadanos inscritos y el Parlamento virtual. En el material difundido por los creadores del Parlamento virtual, se puede analizar la naturaleza de este proyecto que ya se encuentra en una fase avanzada: «nuestro partido propone ser ese caballo de Troya, que jugará al juego democrático actual, para cambiarlo desde dentro. Si, a través de nuestros escaños, podemos llevar a las cámaras lo que opina la gente en Internet, habremos implementado una Democracia Líquida dentro del sistema actual con la intención de crecer y que, finalmente, los partidos sean meros movimientos de opinión en el propio sistema de votación por Internet. En ese momento habremos cambiado el sistema. Por lo tanto se trata de un partido político herramienta, sin ideología propia. La afiliación es gratuita y se financia a base de donaciones voluntarias. Las cuentas son públicas y las listas para las elecciones abiertas. Al reflejar la opinión de todos los que voten a través de Internet, no tenemos una tendencia política establecida, y esto puede ser la llave para acabar con el bipartidismo» ${ }^{28}$.

Técnicamente, «el sistema planteado no votará en masa. Los diputados de PDI en las cámaras de representación votarán proporcionalmente lo que se haya votado en Internet ${ }^{29}$. Con esta práctica, la idea es la de reflejar fielmente las decisiones tomadas mediante internet en el nuevo Parlamento.

Sin embargo la creación de un Parlamento virtual, actualmente debe enfrentarse a la rigidez constitucional española en materia parlamentaria.

${ }^{26}$ En la relación internet, Parlamento y participación política, Vid. LeIVA, L. «Internet, participación política y parlamento», Politikós: estudios políticos e internacionales, núm. 1, 2003, págs. 85-96.

27 Señalamos que en España ya existe y se entrega a los ciudadanos el Documento Nacional de Identidad Electrónico (DNIe).

${ }_{28}$ Vid. http://partidodeinternet.es/wp-content/uploads/2012/11/apuntes_para_el_ponente.pdf

[Fecha de consulta 10 de diciembre de 2013].

${ }_{29}$ Es decir, p.ej., si un $20 \%$ votará que SÍ, un 30\% votará que NO y hubiera un $50 \%$ de votos en blanco en unas votaciones dadas, y el PDI tuviera 10 escaños, entonces 2 de ellos votarían que SÍ, 3 que NO y 5 se abstendrían. 
La principal preocupación reside en el art. 66.2 y 70 de la Constitución Española. En el primer caso: «Las Cortes Generales ejercen la potestad legislativa del Estado, aprueban sus Presupuestos, controlan la acción del Gobierno y tienen las demás competencias que les atribuya la Constitución».

Al estado actual, el Parlamento ejerce una función de control sobre el gobierno es decir, el Parlamento se convierte en la institución en la cual se critica o se apoya el Ejecutivo influyendo en las decisiones de los gobiernos que se repercuten en los ciudadanos. En esta línea, el Parlamento virtual resulta ser una buena herramienta para tomar las decisiones pero al mismo tiempo falta el seguimiento necesario a través del cual los ciudadanos/representantes que ocupen un escaño digital en el Parlamento virtual puedan ejercer la función de control que en su vertiente clásica sirve para la construcción de la democracia.

A esta cuestión se suman las causas de inelegibilidad propuestas en el art. 70 de la Constitución Española. Si por un lado el constituyente español previó unas causas legales de inelegibilidad (a través de la Ley electoral, por ejemplo), por el otro, es necesario que el Partido de Internet indique tajantemente cuando un ciudadano queda excluido de la posibilidad de ser nombrado representante y entonces ocupar el escaño digital.

De hecho, en el formulario de afiliación al Partido de Internet (teóricamente un afiliado puede ser nombrado representante), se solicitan datos comunes (nombre, apellidos, sexo, nacionalidad, dirección etc.) y una copia del Documento de Identidad, no se hace referencia, por ejemplo, al estatus judicial de la persona ${ }^{30}$.

\section{CONCLUSIONES}

Nadie puede objetar que la sociedad española, como la de otros países europeos (y mundiales), está sufriendo una fragmentación entre la política y las exigencias sociales de sus ciudadanos. La distancia, en términos de contenidos, es cada vez mayor: si España sigue las líneas guías introducidas por la Unión Europea actuando según fuertes políticas de austeridad, los ciudadanos que se empobrecen cada vez más demandan cambios contundentes. Este empobrecimiento no es solamente económico sino más bien se reconoce en la pérdida de derechos principalmente sociales dificultando entonces la (re)construcción del estado de bienestar.

La democracia líquida plantea una nueva forma de gestión de los intereses públicos.

${ }^{30}$ Vid. http://www.democracialiquida.org/sect/es_ES/20000/Afiliaci\%C3\%B3n.html [Fecha de consulta 10 de diciembre de 2013]. 
Sin embargo, la democracia líquida, en el actual sistema, no parece ser suficientemente madura para reemplazar la manera más clásica (y reprobada) de hacer política y tomar las decisiones. Al mismo tiempo caben destacar las profundas potencialidades que este tipo de participación política puede ofrecer.

Las críticas (que esperan ser constructivas) de este trabajo han de verse en perspectiva futura, es decir, como elemento de debate para mejorar un sistema de democracia que puede tener algún logro.

Pese a que la democracia líquida podrá ofrecer resultados en un futuro próximo, no podemos olvidar la responsabilidad de la actual política. Principalmente, la clase política actual (de derecha y de izquierda) debe asumir el gran fracaso de su gestión más aún en la situación económica que España está viviendo. Los recortes y la política de austeridad afectan al estado social y de bienestar cuando, por lo contrario, en situaciones de emergencia no deberían verse perjudicados sino totalmente amparados.

Los partidarios de la democracia líquida asumen elementos claros para acabar con este tipo de política, en particular identifican la delegación del voto y la construcción de un Parlamento virtual como dos herramientas prioritarias. En este sentido y sin ánimo de profundizar, vale la pena realizar algunas consideraciones.

Es necesario (re)plantearse la construcción de la cuestión democrática. El individuo como persona debe retomar su papel principal. Para hacer esto es responsabilidad de los actuales partidos políticos volver a hacer «trabajo de campo» con sus electores. Actualmente los partidos políticos han perdido su relación con los votantes. Sólo durante las campañas electorales los representantes políticos se reúnen con los electores. En primer lugar, este acercamiento resulta necesario puesto que los partidos políticos siguen siendo fundamentales para la construcción de la cuestión democrática. En segundo lugar es esencial restablecer la confianza entre el elector y los partidos políticos.

No parece tan clara la posición de la democracia líquida sobre quienes son los destinatarios de sus ideas. Resulta demasiado utópico pensar que este tipo de democracia representa a todos. La preocupación, finalmente, no es solamente relativa a la posible construcción de un Parlamento "diferente» (virtual), sino más bien a cómo se tomarán las grandes decisiones sociales si los que representan el Partido de Internet (con el voto delegado), tienen ideas políticas diametralmente opuestas. No debe engañar el hecho de que el Partido de Internet se declare apolítico. Este partido estará compuesto por personas que tienen su idea. Tampoco podemos aceptar que el representante del Parlamento virtual sea un mero «apoderado» de las ideas de otros. En términos teóricos, también los actuales parlamentarios son los «apoderados» de los electores (de una determinada parte política). Esto sí, los partidarios de la democracia líquida establecen que los representantes se elijan directamente. 
Es probablemente en este punto donde ésta corriente democrática puede lograr mayores resultados. Al mismo tiempo, la respuesta de la política clásica podría ser que existen las Primarias para la elección de los representantes políticos. Si por un lado esto es cierto, por el otro preocupa la posición que puede asumir el político, dentro de su partido y en el Parlamento. De hecho, la Constitución española prevé, en su art. 67.2 la prohibición del mandato imperativo del partido político hacia el candidato electo. La problemática se produce cuando los partidos, en ejercicio de la denominada disciplina de partidos, deciden expulsar a quien ya ostenta un cargo o representación política en el momento en que el político rompe con la disciplina de su partido político a través del cual accedió al cargo.

Si el candidato representa el «apoderado» de los ciudadanos que lo han elegido a través de las Primarias, será necesario revistar el dictado constitucional en este apartado.

La creación de un Parlamento virtual y entonces la desaparición, paulatina, del Parlamento ordinario parece ser un llamamiento populista. Las funciones constitucionales del Parlamento son tantas e importantes pero quizás, la más elemental es la de representar la democracia de un país donde las diferentes partes políticas se enfrentan para que se adopten las mejores decisiones de política interna y de política internacional. El Parlamento virtual no parece identificar estos tipos de características.

Finalmente, la utilización de las plataformas digitales para la instauración de nuevas formas de democracia, resulta, en el estado actual, una realidad imprescindible que debe ser considerada por todo su potencial. En este sentido, es útil avanzar en este sistema para establecer opiniones comunes que respondiendo a necesidades ciudadanas se eleven a las instituciones correspondientes. Dicho de otra forma, las herramientas de la democracia líquida tendrían que seguir el camino de la democracia participativa que utiliza internet y la era 2.0 como instrumento para dar voz a los ciudadanos. Esta voz, como ha sido mencionado, deberá ser llevada a las instituciones que tendrán la obligación de acatar la soberanía popular y actuar según las indicaciones populares.

\section{BIBLIOGRAFÍA ESENCIAL}

BaUman, Z., «Modernidad Liquida», Fondo de Cultura Economica USA, 2003

BECK, U., «Risk Society: Towards a New Modernity», Londres, 1986

BLANCO VALdÉs, R.L., Las conexiones políticas. Madrid: Alianza Editorial, 2001

BobBio, N., «Estado, gobierno y sociedad: por una teoría general de la política», Editorial Fondo de Cultura Económica, México, 1989

CELA, J., «Sociedad del conocimiento y sociedad global de la información: Implantación y desarrollo en España», Documentación de las Ciencias de la Información, Vol. 28, 2005 
Donati, D., Partecipazione come categoría. Identitá e raprresentanza. Ruolo e contraddizioni delle nuove forme associative en Valastro A. Le regole della democracia partecipativa. Itinerari per la costruzione di un método di governo. Napoli: Jovene Editore, 2010

FERRAJOLI, L., «De la carta de Derechos a la formación de una esfera pública europea», en CARbonell, M., Salazar, P. (editores), «La constitucionalización de Europa», Universidad Nacional Autónoma de México, Instituto de Investigaciones Jurídicas, México, 2004

Ganuza Férnandez, E., Álvarez De Sotomayor, C., «Ciudadanía y democracias: los presupuestos participativos», en GANuZA Fernández, E., Álvarez DE SotoMAYOR, C (Coords.), Democracia y presupuestos participativos, Barcelona, Icaria, 2003

LARA GonZÁlEZ, J.D., «Sociedad del conocimiento en medio de una sociedad del desconocimiento», Nómadas Revista Crítica de Ciencias Sociales y Jurídicas, España, Vol. 32 núm. 4, 2011

LeIVA, L. «Internet, participación política y parlamento», Politikós: estudios politicos e internacionales, núm. 1, 2003

LóPez CEREzo, J., «Gobernabilidad en la sociedad del conocimiento», Eidos Revista de Filosofía de la Universidad del Norte, núm. 6, mayo, Colombia, 2007

Mateo, J.L., «Sociedad del conocimiento», Arbor Ciencia, Pensamiento y Cultura, Vol. CLXXXII núm. 718 marzo-abril, Madrid, 2006

NANCY, J.L., «La verdad de la democracia», Amorrotu Editores, Buenos Aires-Madrid, 2009

PITKIn, Hanna F., The Concept of Representation. Berkeley: University of California Press

RÁMIREZ NÁRDIZ, A., «La participación como respuesta a la crisis de la representación: el rol de la democracia participativa», Revista de Derecho Político núm. 90 mayo-agosto 2014

RöDel, U., Frankenberg, G. y Dubiel, H., «La cuestión democrática», Huerga y Fierro Editores, Madrid, 1997

SARTORI, G., «Elementi di teoría política», Il Mulino, Italia, 1989

¿Qué es la democracia? Madrid, Tarus, 2012

\section{BIBLIOGRAFÍA EN LÍNEA}

CARDENAS GARCÍA, Jaime, «Democracia interna en los partidos y democracia participativa», <www.juridicas.unam.mx/publica/librev/rev/derestas/cont/1/.../ens8.pdf>

[Fecha de consulta 11 de marzo de 2014]

Spain Digital Future, <http://www.digital-nature.com/uploads/documentos/2013Spain-Digital-Future-in-Focus.pdf $>$

[Fecha de consulta 9 de abril de 2014]

Democracia Líquida, <http:/www.democracialiquida.org/sect/es_ES/4003/ Delegaci\%C3\%B3n+de+Voto.html>

[Fecha de consulta 10 de abril de 2014] 
Partido de Internet, <http://partidodeinternet.es/wpcontent/uploads/2012/11/apuntes_para_el_ponente.pdf $>$

[Fecha de consulta 10 de septiembre de 2014]

Afiliación Partido de Internet, <http://www.democracialiquida.org/sect/es_

ES/20000/Afiliaci\%C3\%B3n.html>

[Fecha de consulta 10 de septiembre de 2014]

TITTLE: Liquid democracy, an alternative to classical politics? A contextual study.

RESUMEN: Desde hace tiempo se habla de la (re)construcción de la cuestión democrática mediante la utilización de sistemas de democracia participativa. La democracia líquida se sirve de la tecnología y de internet para intentar construir una nueva manera de entender la política ciudadana. La delegación del voto y la instauración del Parlamento virtual representan dos de los elementos para llevar a cabo los criterios de la democracia líquida. Este trabajo, abordando el estado de la sociedad del conocimiento, que es donde se desenvuelve la democracia líquida, intenta analizar una realidad que aún no plenamente madura puede tener la capacidad de revisar novedosamente el concepto de política participativa.

PALABRAS CLAVE: democracia líquida, parlamento virtual, delegación del voto, cuestión democrática, participación.

ABSTRACT: Re-constructing the issue of democracy using participatory democracy systems, has been discussed for a while. Liquid Democracy uses technology and Internet to try to build a new way to understand public policies. The proxy voting and the establishment of a virtual parliament, represent two elements to carry out the criteria of liquid democracy. This work, addressing the state of the society of knowledge where democracy turns liquid, try to analyze a reality that even with it's immature condition, may have the ability to innovatively review the concept of participatory politics.

KEY WORDS: liquid democracy, virtual parliament, proxy voting, democratic issue, participation. 